\title{
ESTACIONAMENTO DE VEÍCULOS - GRATUIDADE COMPULSÓRIA - INCONSTITUCIONALIDADE
}

Inconstitucionalidade de lei estadual que veda cobrança aos usuários pelo estacionamento de veículos.

\section{PARECER}

A consulta tem como objeto a apreciação de constitucionalidade da Lei $n^{\circ} 2.050$, de 30 de dezembro de 1992 do Estado do Rio de Janeiro, que acrescentou preceito novo à Lei estadual $n^{\circ} 1.748$, de $1^{\circ}$ de novembro de 1990 . Segundo o texto original, dispõe o art. $1^{\circ}$ da última lei:

A pessoa física ou jurídica, independente do ramo de sua atividade, que ofereça ao público área própria ou de terceiro, para estacionamento de veículos automotores no Estado Rio de Janeiro, fica obrigada a manter empregados próprios nas entradas e saídas das dependências destinadas a tal fim e a cercar o parqueamento ao ar livre".

A esta norma, em si mesma onerosa, foi aditado pela primeira lei citada, parágrafo único assim redigido:

"Fica vedada a cobrança ao usuário do estacionamento a que se refere esta Lei, de qualquer quantia pela sua utilização".

Estabelece, ainda, $o$ art. $4^{\circ}$ da referida Lei $n^{\circ}$ $1.748 / 90$, a responsabilidade civil do título estacionamento, em caso de roubo ou roubo do veículo.

Prevê finalmente, que, em lei, os municípios estabelecerão normas próprias sobre o estacionamento de veículos em logradouros públicos, dando à segurança dos bens e da população. O exame da questão de constitucionalidade norma legal em causa impõe a fixação de premissas, a seguir expostas, de modo a permitir a conclusão sobre o mérito da indagação.

É mister, primeiramente, considerar a validade jurídica da imposição de dever jurídico de gratuidade a quem permite o estacionamento em bem de seu domínio ou posse.
Subsidiariamente, cabe avaliar a competência do Estado-membro para legislar sobre a matéria.

\section{II}

A história constitucional republicana oscila em alternância entre os princípios da liberdade e da autoridade. Nos hiatos revolucionários - frutos de movimentos políticos em 1930 , 1937 e 1964 - a balança pende para o reforço do centralismo, com a decorrente limitação do acesso às liberdades públicas. O retorno as garantias fundamentais que a eles se sucede, definido em novas Cartas Constitucionais - as de 1934,1946 e 1988 -tende a fortalecer a cidadania e a liberdade individual, inclusive pelo oferecimento, ou ampliação, de remédios especiais que as assegurem.

Simultaneamente avessa feição dinâmica do processo histórico, também se evidencia o movimento pendular, no plano da federação, entre o predomínio do poder central e o fortalecimento da autonomia dos Estados-membros. A fórmula clássica do federalismo dual - em termos de competência verticais que distribuem, paralelamente as atribuições evolui, à feição dos modelos de direito comparado, para o federalismo cooperativo, no qual União e Estados se associam para a prestação de serviços sociais e, modernamente, alcança o federalismo de integração, em que até mesmo se confundem os poderes autônomos visando a objetivos comuns (ver, a respeito, MANOEL GONÇALVES FERREIRA FILHO - Curso de Direito Constitucional $17^{\mathrm{a}}$ edição - 1999 - p. 45). 
O intervencionismo do Estado na ordem social e econômica, estimulado pelas crises de após-guerra, prestigia a discricionariedade do legislador e, por via reflexa, do Poder Executivo, no planejamento e na execução da política de justiça social.

Ao mesmo tempo, porém, as declarações fundamentais de direitos e liberdades marcam a presença do cidadão e do indivíduo como os destinatários finais da ação democrática de governo.

Outro fator peculiar à ordem jurídica contemporânea é o papel da empresa privada como agente social. As liberdades públicas protegem não somente os indivíduos, como pessoas físicas, mas também quando, associados em interesses e aspirações, realizam seus objetivos por intermédio de pessoas jurídicas.

No plano constitucional o empresário é, a um tempo, agente ativo do desenvolvimento social e titular de direitos e liberdades, na medida em que a ordem econômica pressupõe a iniciativa privada.

ALFREDO LAMY FILHO e JOSÉ LUIZ BULHÕES PEDREIRA, em notável estudo sobre a sociedade comercial moderna, destacam a relevância da função social da empresa nos regimes de economia aberta:

"A diferença entre as duas concepções de organização social que polarizam o mundo atual reside, basicamente, na definição dos agentes da função empresarial. E o modo pelo qual organizamos hoje o exercício dessa função determinará o modelo econômico e político da sociedade brasileira no futuro. Se não conseguirmos criar condições que permitam ao empresário privado brasileiro desempenhá-la, nos grande projetos, em competição com o Estado e as multinacionais, teremos um regime de monopólio de fato, pelo Estado, da função empresarial, a que se seguirá, natural e inexoravelmente, o monopólio do direito" (A lei das S.A. - edição Renovar - 1992 - p. 205).

III

A Constituição do Império, como a primeira Constituição republicana, fiéis à pureza do li- beralismo clássico, asseguravam o direito de propriedade "em toda sua plenitude", apenas limitado pelo poder expropriatório, perante o qual o domínio cede em face do interesse público, mediante indenização (Constituição de 1824, art. 179, $\mathrm{n}^{\circ} 22$; Constituição de 1891, art. $72, \S 17$ ).

A Constituição de 1934 sensível aos novos vestos dos direito constitucional - expressos pioneiramente na Constituição mexicana de 1917 e a de Weimar, em 1919 - inaugura o título sobre a Ordem Econômica e Social, impondo limites à liberdade econômica, vinculando-a aos princípios da justiça social e às necessidades da vida nacional (art. 115).

A partir de então o teor absoluto do direito de propriedade e a liberdade de contratar encontram disciplina legal em atendimento a finalidades sociais relevantes.

A Ordem Econômica continua presente nas Constituições brasileiras subseqüentes, até a atual, com tônicas diversas, segundo a posição intervencionista ou neoliberal em face do bem público (Constituição de 1937, art. 135 e seguintes; Constituição de 1946, art. 145 e seguintes; Constituição de 1967/69, art. 160 e seguintes).

A Constituição de 1988, a par da valorização do trabalho humano e da ênfase nos ditames da justiça social, marca, desde o seu preâmbulo, o signo da liberdade como expressão de uma sociedade aberta e pluralista.

A livre iniciativa é prestigiada como um dos fundamentos do Estado Democrático de Direito (art. $1^{\circ}, \mathrm{n}^{\circ} \mathrm{IV}$ ) e da Ordem Econômica, com a observância, entre outros, dos princípios da propriedade privada, da livre concorrência e do direito de propriedade, atendida sua função social (art. 170, caput e item II, III e IV).

A atividade econômica é, por excelência, campo próprio à liberdade de mercado, com a firme definição da excepcionalidade da exploração estatal direta em caso de monopólio ou condicionada aos imperativos da segurança nacional ou a relevante interesse coletivo, a serem definidos em lei federal (arts. 173177). 
A norma pública de planejamento, reguladora da atividade econômica, será apenas indicativa para o setor privado (art. 174).

Significativamente, o art. 219 firma a importância da economia de mercado como fator de desenvolvimento, em termos expressivos, acolhendo o princípio de que "o mercado interno integra o patrimônio nacional", a ser incentivado pela lei federal de modo a viabilizar o desenvolvimento nacional.

Nos trâmites da Assembléia Constituinte, GERALDO DE CAMARGO VIDIGAL enfatizou o relevo desta iminente norma constitucional:

"É que o regime que consagra a livre iniciativa e o trabalho e, por sua natureza, um regime econômico de mercado. Livre iniciativa só pode existir quando os mercados funcionam. Mais ainda: a liberdade de iniciativa engendra ela mesma os mercados, quando o direito de propriedade e a prevalência da autonomia de vontade, nos contratos, compõem o regime jurídico-econômico" (A Constituição Brasileira 1988 - Interpretações - edição da Fundação Dom Cabral e da Academia Internacional de Direito e Economia - Forense Universitária - 1988 - p. 379).

A aceitação do princípio da economia de mercado não exclui a disciplina da lei afeiçoando-a aos fins sociais que identificam sua harmonia com os interesses coletivos, em busca da justiça social. Todavia, o papel da lei, excepcional por definição, não contesta o direito fundamental da liberdade, antes o confirma em sua precípua destinação.

EROS ROBERTO GRAU, trazendo à colação os intérpretes do modelo constitucional, destaca que "a ordem econômica na Constituição de 1988 consagra um regime de mercado organizado" e, em síntese final, conclui que a ordem econômica, no esquema constitucional vigente contempla a economia de $m \in \mathrm{r}$ cado, embora distanciada do modelo liberal puro. Repudia o dirigismo estatal, de modo que no intervencionismo econômico não se faz contra o mercado, mas a seu favor (A Ordem Econômica na Constituição de 1988 interpretação e crítica - Edição Revista dos Tribunais - 1990 - pág. 211/212).
Em suma, a livre iniciativa e a liberdade de contrato estão nas bases da ordem econômica, atendidas as finalidades sociais a que se devem amoldar tento o direito de propriedade como a função da empresa privada.

A liberdade econômica é a regra; deveres limitativos são a exceção motivada pelos fins que os inspirem. Como norma geral a pessoa física ou jurídica é o juiz de seu próprio interesse, segundo as vantagens que legitimamente pretenda auferir.

E a imposição de deveres ou ônus, que condicionam os direitos individuais não poderá ser discricionária, mas diretamente vinculada a um fim social determinado e específico.

\section{IV}

O Estado Federal, oriundo da República, tem, como antes assinalado, entre suas características, a repartição de competência entre a União a os Estados-membros.

A concentração própria dos poderes da União se equilibra com o princípio descentralizador da autonomia estadual (e já agora também municipal) que, no entanto, gravita como satélite em torno da coluna mestra da unidade nacional.

A força centrípeta da organização do Estado Federal tem como instrumento essencial a competência privativa da União para legislar sobre as matérias arroladas no artigo 22 da Carta Constitucional.

A estrutura básica do ordenamento jurídico da economia é reservado privativamente à União, com exclusividade de legislar sobre direito civil, comercial, processual e do trabalho.

É a lei federal que incumbe traçar rumos à liberdade econômica e de contrato, pilares da economia privada. Não cabe à lei estadual ditar procedimentos, ou estabelecer condicionantes, em razão dos quais devam os particulares sugerir seu patrimônio, administrar seus negócios, celebrar seus contratos e assumir obrigações no plano das relações civis e comerciais.

A função social da propriedade, ou as limitações da empresa na economia de mercado não cabe à lei estadual ordenar ou dirigir. 
Nos assuntos de competência legislativa privativa a lei federal é soberana e exclusiva, apenas ressalvada, a título excepcional, a possibilidade de delegação de competência que lei complementar possa conceder, em caso específico. ao legislador estadual (parágrafo único do art. 23 da Constituição), prevalecendo sempre a hierarquia superior da fonte normativa federal.

A lei estadual que exorbite, como intrusa, invadindo os lindes da competência privativa da União, é, por consequiência, inconstitucional.

\section{V}

A luz destas premissas é que se impõe definir a constitucionalidade da lei estadual objeto da consulta.

Nela se dispõe, sucessivamente, um elenco de limitações e imposições à vontade das pessoas físicas ou jurídicas que, conforme a terminologia legal, "ofereçam ao público" locais próprios ou de terceiros para o estacionamento de veículos.

De tais ofertas resultam, segundo a lei em causa, deveres e responsabilidades. Terão os ofertantes de fornecer serviços de controle e segurança que assegurem a integridade do veículo, respondendo pelos danos que a eles venham a ser causados. E terão de sujeitar-se à gratuidade de tais serviços e do uso do bem de seu domínio ou posse, no qual ocorra o estacionamento.

Contudo, o estacionamento consentido corresponde a uma relação contratual que se define pela oferta e se completa com a aceitação ou adesão do usuário. É negócio jurídico consensual, tanto na formação como no efeito jurídico decorrente do acordo de vontades que nele se integram. Insere-se no plano do direito civil que, como realçado, é matéria privativa da lei federal, consequientemente imune à lei estadual.

A rigor, nem mesmo a lei federal poderia constranger a particular à gratuidade da cessão de uso da área reservada, ao estacionamento e ao mesmo tempo impor-lhe deveres de garantia da incolumidade de bens e de responsabilidade civil em caso de dano.
A liberdade de contratar e as faculdades inerentes ao direito de propriedade não serão compatíveis com violações deste porte.

E se assim estará vedada ao legislador federal a prática de tais atos inconstitucionais, com maior soma de razões se tornam inacessíveis ao legislador estadual.

Duplamente inconstitucional é, em suma, o ditame da lei estadual posta em análise. Seja materialmente pela ilicitude do conteúdo, seja formalmente pela ausência de competência legislativa para regular a matéria.

\section{VI}

Nem se pretenda trazer em apoio da lei estadual impugnada a competência concorrente para defesa do consumidor.

O Código de Proteção ao Consumidor (Lei $\mathrm{n}^{\circ}$ 8.078, de 14 de setembro de 1990) define, como tal, a pessoa física ou jurídica que utilize produto ou serviço como destinatário final (art. $2^{\circ}$ ).

Não se colocam, obviamente no âmbito da lei em referenda, os que explorem, diretamente, o estacionamento licenciado como tal. A própria natureza da atividade repele, por definição, a gratuidade incompatível com a comercialidade do serviço.

A lei estadual visualiza o estacionamento oferecido em centros comerciais ou assemelhados, nos quais a disponibilidade de áreas acessiveis aos frequientadores opera como estímulo à clientela. A relação constituída de tal forma independe do ato de comércio que se possa vir a consumar, mais representa atividade-meio que não importa em relação de consumo.

Tal como em outras formas de estímulo ou atrativo, o estacionamento permitido é ato de vontade do comerciante (ou do complexo comercial), ao qual caberá dispor sobre a oportunidade e forma de uso da propriedade da maneira mais conveniente aos seus interesses.

Se o estacionamento deverá ser gratuito ou oneroso, limitado no tempo ou atraso indeterminado, sujeito a espaço determinado ou não, são assuntos da economia interna do titular da área, não lhe podendo ser imposta a gratuidade ao mesmo passo que se lhe atribui o ônus de fiscalização e segurança do uso oferecido. 
Será indevida a intervenção do Poder Público (e a fortiori do poder público estadual incompetente ratione materiae) no sentido de impor a gratuidade de serviços que são virtualidades do domínio ou posse privados.

A autonomia da vontade permitirá ao utente adotar o regime adequado à finalidade privada que visa a alcançar, como medida promocional de seu negócio principal. Descabe ao legislador sobrepor-lhe seu comando imperativo para ordenar o regime gratuito dessa relação secundária, ofendendo o princípio constitucional da livre iniciativa.

VII

A atual Constituição brasileira colhe, em seu âmbito, o princípio do devido processo legal, tradicionalmente presente no direito constitucional norte-americano (due process of law).

Assegura o art. $5^{\circ}$, item LIV da Constituição de 1988 que "ninguém será privado da liberdade ou de seus bens sem o devido processo legal". A vedação se endereça à ilicitude de, ação que importe impedimento total ou parcial a direito ou liberdade. A interdição se dirige tanto ao administrador como ao legislador.

Não se trata apenas de garantia processual, como originariamente se entendeu a destinação do princípio pela sua literalidade.

A doutrina e a jurisprudência norte-americanas qualificaram adequadamente o substantiv'e due process, ou seja, a vedação de lei atentatória do conteúdo do direito ou liberdade a que falte o requisito de razoabilidade.

$\mathrm{O}$ apelo à cláusula constitucional do due process, em termos de substância, tem sido na jurisprudência da Corte Suprema o veículo por excelência de repulsa a leis discriminatórias ou de privilégio que se opõem a plenitude de direitos constitucionais, em matéria social ou econômica

O controle de constitucionalidade submete os atos legislativos ao teste de racionalidade (rationality test) pelo qual se examina a compatibilidade razoável entre a limitação da liberdade ou do direito de propriedade e o fim legitimamente permitido à atividade de governo (ROTUNDA, NOWAK e YOUNG Treatise on Constitucional Law - Substance and Procedure - volume 2 - 1986, p. 64/65 e p. 7 do Suplemento de 1991).

JERRY L. MASHAW destaca o relevo da cláusula do due process na essência do processo democrático:

"If habeas corpus is the "Great Writ", due process must sure be the "Great Clause"

(Se o habeas corpus é a "Grande Ordem", o devido processo legal deve certamente ser a "Grande Cláusula")

(Due process in the Administrative State Yale University Press - 1985 - p. 2).

A Constituição portuguesa adota o princípio da adequação das normas limitativas de direitos e liberdades (art. $18, n^{\circ} 2$ ), sublinhando CANOTILHO que, embora livres em princípio os fins perseguidos pelo legislador "é admissível a fundamentação de uma decisão de inconstitucionalidade com base no principio da proporcionalidade, o que acaba em geral num juízo sobre a adequação e inadequação de meios e fins" (Direito Constitucional $-5^{\text {a }}$ edição - 1991, p. 1.028, grifo do original).

A Constituição espanhola abrigou, expressamente, a "interdição de arbitrariedade dos poderes públicos" (art. $9^{\circ}, n^{\circ} 3$ ) como proteção aos valores superiores do ordenamento jurídico, entre os quais o art. $1^{\circ}$ da Constituição registra a liberdade, a justiça e a igualdade.

$\mathrm{Na}$ lição de GARCIA DE ENTERRIA

"Io que a probicion de la arbitrariedad condena es, justamente la falta de un fundamento objetivo; la Constitucion non admite que el poder publico en qualquiera de seus expressiones, se ejerza por la solo voluntad del agente o por su capricho, simplemente" (Es inconveniente o inultil la proclamación de la interdiccion de la arbitrariedad como princípio constitucional? - in Revista de Administración Publica - volume 124 - janeiro-abril 1991 - p. 225).

Conforme advertência de GILMAR FERREIRA MENDES, inspirada no direito alemão, o princípio da proporcionalidade representa, entre nós, típica manifestação de excesso do poder legislativo, na medida em que a norma legal importe "contrariedade, incongruência e irrazoabilidade ou inadequação entre meios e fins" (Controle de constitucionalidade - Aspectos jurídicos e políticos Editora Saraiva - 1990 -.. F. 12). 
JUAN FRANCISCO LINARES, em tese doutoral da década de 60 , reeditada em 1989 como estudo sobre "Razoabilidad de las leys" (Editorial Astrea) demonstra a recepção do princípio do "debido proceso" como garantia inominada no regime constitucional argentino.

\section{VIII}

Por todo o exposto, somos de parecer que a regra de gratuidade compulsória dos estacionamentos de veículos, prevista na lei estadual em estudo, é inconstitucional por múltiplos fundamentos.

Primeiramente, porque descumpre o respeito aos princípios constitucionais de liberdade de iniciativa e de contrato e o da disponibilidade do direito de propriedade ao seu titular.

Em segundo lugar, porque padece de vício formal quando interfere no regime jurídico de uma relação civil e comercial (contrato de adesão ao uso e estímulo a atos de comércio), violando competência privativa da União.
Ademais, pela ausência de razoabilidade, cria dever incompatível com a substância do princípio do devido processo legal na medida em que impõe obrigação onerosa de fazer na guarda do veículo e a responsabilidade civil por dano, ao passo que obsta o nexo de proporcionalidade quando prescreve a vedação absoluta de cobrança ao usuário do estacionamento, ao arrepio da vontade livre do titular do domínio ou posse da área utilizada.

E não satisfeito de tantas eivas de inconstitucionalidade, extrema-se em ordenar aos municípios o estabelecimento de normas sobre a matéria, implicitamente na linha esposada pelo legislador estadual.

A manifesta inconstitucionalidade que vicia o ato legislativo estadual poderá ser declarada na via judicial tanto em ação própria (controle concentrado) como mediante exceção em outro feito (controle difuso).

Este é nosso parecer.

Rio de Janeiro, 15 de fevereiro de 1993. Caio Tácito - Professor Emérito da Universidade do Estado do Rio de Janeiro. 